\title{
Engagement Levers for Therapists and Patients in a Context of Cognitive Rehabilitation of Executive Functions With the Serious Game S'TIM
}

\author{
Julie Golliot \\ Clinique RGDS Provence-Bourbonne \\ \& Laboratoire IMSIC Toulon \\ Toulon, France \\ julie.golliot@ensc.fr
}

\begin{abstract}
This vision paper focus on a context of cognitive rehabilitation for patients with dysexecutive syndrome, where therapists and patients' engagement is crucial for the therapy' success. Based on theories of multiples scientist fields, a usercentered methodology was developed and a serious game was designed with a multidisciplinary team. Using this device with their therapists put patients at the heart of their rehabilitation and give them a chance to make socio-affective and socioaffective changes, to develop their own mental constructs and to go back to their daily life.
\end{abstract}

Keywords-Game Based Learning - Game design-Cognitive Rehabilitation - Engagement - Dysexecutive syndrome - UX Design.

\section{INTRODUCTION AND CONTEXT}

In a context of healthcare undergoing many changes, which are not only medical but also political, institutional and organizational, more and more healthcare institutions are looking for new technologies. The objective is twofold: On the one hand, to diversify and to expand the care offer in order to go beyond its current limits. On the other hand, to distinguish itself in the medical ecosystem, to be more attractive and to facilitate the recruitment of patients.

The present paper aims to introduce a new device focused on user engagement and designed for health care institutions to stand out from competition.

Rehabilitation centers are therefore highly exposed since they want patients to choose their center rather than another one, because their survival depends on the number of patients they take care of. In this context, tools based on video games and more precisely Serious Games are particularly attractive. Studies show that these games please patients [1] and therapists [2]. They are also complementary, supporting and in some contexts, they can produce therapeutic effects [3].

The issue of motor rehabilitation has been tackled in but cognitive rehabilitation is frequently set aside. Many cognitive disorders are forgotten. Among people with cognitive deficits, those with a dysexecutive syndrome are waiting for new rehabilitation solutions [4]. Executive functions, or control functions, are implicated in cognitive processing requiring coordination of several sub-processes to achieve a specific goal [5]. These processes are involved when it is necessary to be focused on a task, to memorise and to handle information, to adapt to unusual environments or rules and more generally when habits and reflex actions are insufficient [6], [7]. For instance, when the usual route is up for re-construction, another way must be found. These functions are also linked to some attentional processes such as information selectiveness, attention division (mostly in multitasking, e.g. to think about the shopping list while being focused on checking if there is no car when crossing the street). Usually, they are set up during childhood, but they can be deteriorated thereafter. The dysexecutive syndrome concerns among others 40 to $60 \%$ of stroke victims, Parkinson' patients, people with attention deficit with or without hyperactivity and victims of head injury [5]. The following functions are impaired [5]:

- Inhibition, which consists in the voluntary control of answers, behaviours or distractors. With inhibition, an appropriate social behaviour is displayed in various contexts (non-impulsiveness in the case of the behaviour);

- Updating, which favours the encoding of relevant information and mental operations [8];

- Shifting, which is the adaptation of an action plan depending on environmental requirements. Shifting is also required to switch from one task or behaviour to another one (otherwise, perseveration is observed);

- Planning, which is necessary for the temporal organisation and for prioritizing strategy steps to achieve a goal (anticipation and projection);

- Elaboration of strategies (cognitive and metacognitive), which enables to choose the most appropriate way to achieve a goal;

- Attention, which makes the maintenance of the action plan possible until it is actually implemented.

Patients affected by this syndrome are frequently unaware of their difficulties (anosognosia). Their autonomy is highly compromised and today, despite the quality of their rehabilitation [9], only $10 \%$ of them are able to return to their family and work lives.

This vision paper comes back to the theories related to games, serious games and engagement. Then, the method used to engage patients and therapists to maximize the therapeutic potential of the serious game specifically designed and named S'TIM will be exposed. Finally, the limits of S'TIM and the clinical study objectives are explained. 


\section{Method PART 1 : GAMES, SERIOUS GAMES AND PATIENTS'ENGAGEMENT}

\section{A. Interesting serious games characteristics in therapy}

What can be the definition of a game? For Sid Meier, a game is a "series of interesting choices", allowing interactions between the player and the system. A game is also "a system in which players are engaged in an artificial conflict, defined by rules that result in a quantifiable result" [10]. Unlike other consumable medias, the player is actively involved in an activity, which is, in some extent, unpredictable. The affect he brings is the result of mechanics, dynamics and aesthetics (or subjective emotion linked to desire, MDA model). The game theory is rests on the idea that it is an essential that, while game is often associated with childhood, it is a fundamental part of humans whether alone or with others. Getting older does not mean stop playing, although it does not only bring pleasure (a failure to reach a goal for example, can generate frustration). To overcome this effect, the attractivity of the game is essential. Exercises, as well as competition, exert imagination and increase the behaviour flexibility. Playing enhance therefore our resilience.

Video games have five characteristics in common: goal orientation, presence of rules, feedbacks, competition (the most often), voluntary participation of the players. However, as you can ask the learner to work on a Serious Game, this voluntary aspect is not systematic. Unlike other medias, games have three components: intrinsic motivation, reactivity and complexity. Both psychological features implemented here are reward and motivations. Indeed, playing allows to meet specific needs[11], is functional, contributes to cognitive and social development and finally is a pleasant experience: in a nutshell, we like to play. The distinction between "play" (as a fun activity with freedoms) and "game" (as strict rules, competition with a notion of victory or failure, more structured and rigid) is to be emphasized [12]. People like to play to digital games because their architecture is attractive. Feedback could be immediate and comes with a reward. Moreover, success chances increase with trainings and repetitions, which drives the players to continue to involve themselves in the game. More importantly, the player should go beyond failures and frustrations, hence the importance of balancing the game.

Motivated actions are processed within two theories:

- Use and gratifications theory[13]-[15], which is based on the fact that people have specific needs and choose their media according to them. Seven motivations are defined: control (as an actor of the virtual world, the player has some control), challenge (the player should surpasses himself to reach the next level), competition (win or surpass the others), dream (or fantasy: the player is engaged into a quest that can be sometimes difficult, and even impossible in real life. He can therefore test its behaviours and feelings), interest, diversion (get out of everyday life) and finally social interactions (to play with or against others).
- Autonomy and self-determination theory[16], which revolves around three human needs: autonomy (selforganization), competence (in relation to the challenge) and social belonging (to experiment relationships with others). These criteria are great indicators of the tenacity of the player to play. According to this theory, individuals are more inclined to integrate experiences that allow them to express these three needs: An intrinsically motivated activity (regulated in a self-determinate way) is practiced for the sole pleasure of the individual while an extrinsically motivated activity is carried out for external reasons (reward or fear of reprimand, for instance). If the need for autonomy is intrinsically met, the propensity for sustainable learning increases, as do performance, persistence and creativity [17]

\section{B. The essential nature of comitment}

In a therapeutic context, socio-affective and sociocognitive changes are sought. Both patients and therapists must therefore take concrete action to achieve the best possible result. To follow this objective, two prerequisites can be quoted: on the one hand the creation of favourable conditions, and on the other hand the concrete commitment of the actors. One difficulty lies in the gap between ideas (attitudes, beliefs, opinions) and actions [18].

In order to introduce the concept of engagement, the paradigm called "foot in the door" can be presented. This actbased approach consists in performing above all a small request as a preparatory behaviour. Obtaining this behaviour increases the chances that arguments will be taken into account later [19]. This preparatory behaviour precedes the gain of other behaviours that are more expensive. In 1966, Kiesler and Sakumura [20] stated that " commitment is defined as a binding of the individual to behavioral acts ". Joule and Beauvois [21] also highlight the dual characteristic of cause and effect. A link can be established between the individual and his actions only because there is a commitment. Commitment depends on the situation since it involves or not the individual in his actions, which favours or hinders or even prohibits the establishment of a link between him and his actions. It is therefore essential to set up the conditions allowing individuals to make the decision freely by finding good internal reasons for doing so.

To achieve patient's commitment, the necessity is to create new representations. These representations result from perceptions. Because each individual builds his own vision of the world, each one represents it in his own way [22]. Our representation is therefore only partial, partly erroneous but conditions our choices, our perceptions and limits us. Moreover, it is subjective: it relies on the representation we have of reality. It also depends on the received information that is synthesized according to the values, beliefs and experiences. Perception is developed in three stages: Sensory (specialized receptors, retinal for example), Perceptive (formatting of these sensory information) and Cognitive (interpretation of the data, attribution of a meaning to an information). There is thus exteroception (perception of the external environment with our senses), interoception (state of our organism, pain or pleasure), proprioception (ability to 
sense the orientation of the body in the environment) and filtering of data by attention and motivation (only a part of the data is processed at a conscious level). Our perception of the world is thus oriented according to the abilities of our sensory organs but also according to our centres of interest and our previous knowledge [23].

As shown, there are very interesting serious games characteristics in therapy but in order to optimize them, it is needed to consider the notion of commitment in the game design.

\section{METHOD PART 2 : ENGAGEMENT LEVERS}

This section goes into further details on this topic. The key is, however, to pinpoint the importance of the commitment notion in the context of a digital therapeutic device. Above all, e-health systems allow the patients to be active and actor of their own health [24]. The commitment (or the fact of being the principal player) of the patient has benefits on his health and healing [25]. This commitment has three dimensions: emotional (connection with feelings), behavioral (facts and gestures) and cognitive (what the patient understands about his illness and his treatment).

\section{A. Principal foundations}

The patient can be an actor only if he understands his own abilities and the resources he has to engage in technology [26]. Moreover, to be autonomous, he must be able to control information, and therefore to have a sufficient level of health literacy [27]. The Medical Library Association [28] defines health literacy as a "set of abilities needed to: recognize a health information need; identify likely information sources and use them to retrieve relevant information; assess the quality of the information and its applicability to a specific situation; and analyze, understand, and use the information to make good health decisions" Berkman et al., in their systematic reviews, have shown that a patient with high level of literacy is more likely to heal because he has the ability to understand his illness and his treatment [29]. Regarding the impact on user satisfaction and usability of the system, the link with digital literacy level of the patient is also to be considered to. If the patient can operate a device without being able to interpret the data, he will not be engaged and will not reuse the tool.

In practice, the experimentation allowed by the serious game makes it possible to reuse the acquired knowledge. Thanks to competition, personal challenge, the fact that the exercise is different, as well as the feeling of belonging to a community (exchanges), the attention and the adhesion of the players is facilitated. The tool should not be considered only in a descending way: users also have things to say. The game manages the knowledge but also creates it. Video Games immerse the players into complex situations where they have to focus and integrate large data streams. Through missions and quests, the player commits into the game. To solve the algorithms designed by the game-designer, he must establish strategies, anticipate, optimize, make decision, manage his stress, take risks that unleashes his creativity [30]. Unlike other rehabilitation exercises, where patients are not really actors and remain passive, the players have to be pro-active even though fear of failure can paralyze them. Video games can therefore guide the mind, from impossible to possible.

\section{B. Inclusions in the game design}

To carry out their rehabilitation effectively, patients must be attentive, relatively motivated, receptive and have sufficient learning autonomy to reclaim knowledge, skills and know-how. Interactions with caregivers also allow coconstruction and co-development of knowledge. Learning environment thus strongly conditions not only the acquisition or restructuring of knowledge, but also the development of the ability to learn, understand, analyze and master a tool.

The Game Designer must imagine a new world, with game mechanics that will put the patient at the heart of the process, so that they can develop their own mental constructs as a result of their activities, organize their world as they go along and adapt to it. The serious game must therefore stimulate, at higher or lower levels of abstraction, dynamics inspired by the real word. It is a therapeutic tool used to convey a message in a pleasant way, to reinforce the adhesion and the motivation of the players. The serious game must fit the patient's expectations and need, corresponds to novices and regulars and be balanced. This requires a motivating challenge, adapted to the player, and of increasing difficulty. The repetition imposed by operant conditioning, made playful, can cause less weariness and boredom [31] as well as increase self-efficacy and self-management skills which increase motivation. The use of an avatar to which the patient can identify allows him to "embody" and invest himself more easily [32]. It also allows the player to understand several social roles, to develop empathy and to learn to understand each other's points of view and feelings. Social learning would therefore be facilitated.

A balanced serious game (between challenges, ability to play and knowledge of the patient) allows immersion, satisfaction [1] and intrinsic motivation which bring joy, interest, performance, learning quality and self-esteem resulting in a high level of performance and unexpected states of consciousness [33]. Finally, a developed narrative transports the patient and makes him more sensitive to the influence of the messages contained in the story. If all the conditions are met (diversion, immersion, interactivity, transportability), cognitive resources allocated to the serious game and motivation increase, which facilitates the modifications of knowledge [17].

Notions of accessibility, playability and replayability are essential. The appearance and beginning of the serious game must not let the players down and must privilege intuitive actions, hence the importance of User Experience (UX, everything the player can see, hear and interact with and commands). Interactions must make sense. Too many frustrations during the game (but a small dose enhances fighting spirit) must be avoided, and elements of renewal such as chance, narrative aspect of the game (the player want to know the end of the story) and evolution (micro- 
management) should be emphasized for the player to want to play again.

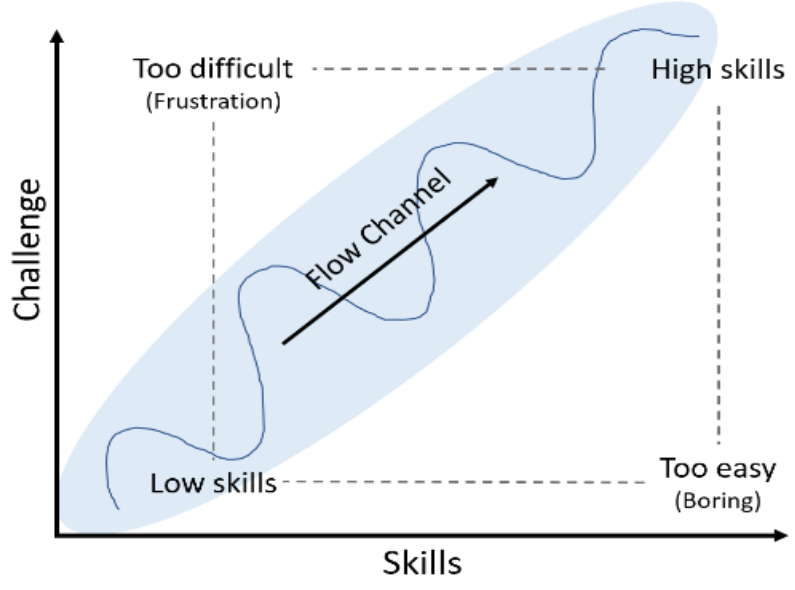

Fig. 1 : Game balance, from Csikszentmihaly [32]

Two notions are intrinsically linked to the game: conflict and cooperation. The conflict occurs very quickly, at the slightest difficulty between the player and his goal. It involves a danger and indices a stimulation. Each individual must feel useful, valued for example by a particular skill. The rules have a huge effect on the players. They are developed to guarantee a balance that will allow the player to remain engaged and interested. Challenges must be progressive: excessive simplicity will lead to disinterest, excessive difficulty will discourage the player (Fig. 1).

Furthermore, with the serious game, therapists can visualize scores and progress of each patient.

Moreover, by adding a persuasive dimension, patients are encouraged to solve playful problems in order to provoke behavioral, socio-cognitive and socio-emotional changes [17]. The serious game will therefore influence the player's attitude, thoughts and feelings, based on psychological and rhetorical theories. Three components are essential: the persuasive properties, the rhetoric of the game and the relation between the game and the patient since the process of persuasion takes place there. Persuasion is then related to changes in attitudes, but not to behavioral ones (which are short-term changes). Additionally, subjects must be free and detached from any obligation. Persuasion can be seen as an interconnection between the game and the players.

With two different approaches, Ian Bogost [34] and Miguel Sicart [35] lead us to consider persuasion as an interconnexion between the game and the players according to two conceptualizations of communication. The first author particularly argues that a particular design is required (predominance of procedural rhetoric) while the second one is more player oriented, since the message of a persuasive game is intrinsic to the action of playing.

Fogg has developed a behavioral model of persuasive design on which he places the system in a continuous space defined by two axes: motivation and aptitudes [36]. The video game must be designed to be adapted to the position of the player on this model, but also to promote these two parameters (engaging activities for self-motivation and activities promoting learning, achievement and feelings of confidence). By its voluntary and goal-oriented nature, a game is an inherent persuasive artifact. It puts forward objectives but in a non-coercive way, like persuasive technologies. A persuasive game therefore exploits figures of manipulation and exploitation.

Nowadays, paper based tests and conventional exercises with board games are inefficient [37]. Moreover, most of virtual tools used by therapists are not ecological, show many similarities with conventional activities and have basic graphics. They are also simple and redundant because of a lack or a poor storyline and narration that harms patients' attraction, immersion and engagement. In this way, serious games potentialities are nor fully exploited [38], [39].

\section{RESULTS: APPLICATION FOR THE DESIGN OF THE SERIOUS GAME S'TIM}

In order to provide a new therapeutic tool in the rehabilitation of dysexecutive disorders, a consortium consisting of a clinical team (doctor specializing in rehabilitation, team of occupational therapists and neuropsychologist) and academics (research team in Information and Communication Sciences) was formed, with the presence of a $\mathrm{PhD}$ student in Cognitics (interactions between new technologies and Human Factors). The multidisciplinary nature of this team led to a deep analysis of the therapeutic practices, as well as the specificities of virtual reality in cognitive rehabilitation.

\section{A. Positioning and scenario}

In order to categorize Serious Games, Djaouti and al., proposed a typology based on the Gameplay / Purpose / Scope model (GPS). Gameplay of S'TIM is therefore based on "the Game"; its objective is to transmit a message, to offer mental training and to allow therapists to exchange data. The scope is therefore medical and users will be the general public (patients) and professionals (therapists). At the beginning of the game, the patient is invited to choose an avatar that he will embody all along the game. An extremely developed scenario has been developed to transport the player into a rich universe, with an engaging narration, which will make him more sensitive to the influences of the therapeutic message contained in the story. For example, the way and the interest to be organized, to memorize information, to interact with people, to plan actions. Patients thus embody a character living in a city almost deserted and wishing to join his friends in paradisiac island. To do this, patients will have to face many challenges who test their executive abilities. As an example, they will have to be attentive and organized to find specific objects in diverse contexts like a house, an office, a forest, a beach. The attention span and the number of items to remember cans be adapted by the therapists. Patients also have to plan their path on a dynamic map and move in a city or in underground passages. Their logic is solicited to resolve puzzles and to plan complex actions (gardening, baking, medical treatments situations). Patients also must remember what they have done and what they have to do to carry out the story. They can refer to a logbook each time they want. It 
mentions the current challenge and objectives, the previous ones and characters they met (Fig 2.).

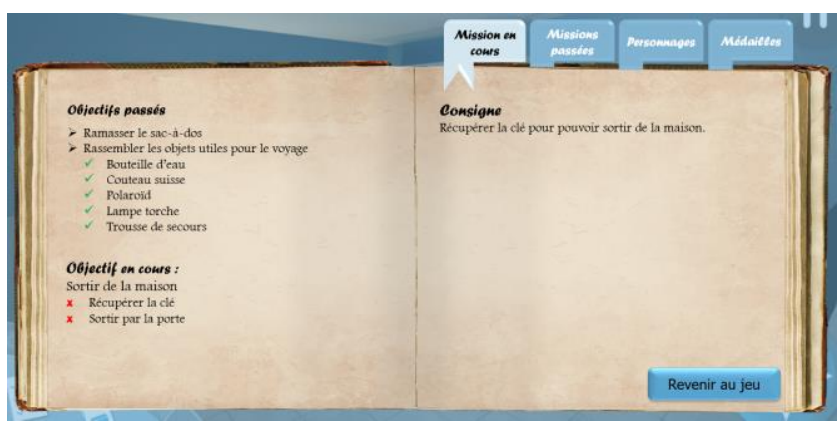

Figure 2: Screenshot of the logbook - current objectives

Goals are multiple: communication (with themselves, game and therapists), inspiration (this guides their decisions), emotions (their empathy is awakened, the immersion facilitated and their receptivity stronger), surprise (promotes thinking and therefore keeps patients motivated and invested), motivation (presence of a concrete goal) and specificity (the serious game is not generic). Moreover, their choices have a true action on the continuation of the story, which allows them to feel as though they were the co-authors. As they try to overcome challenges, their feeling of control is stronger, encouraging them to increasingly invest themselves.

Design of worlds, of objects that are present and plots that are proposed are also highly realistic which allows the patient to live a credible and consistent experience within a significant reality (Fig. 3). During their quest, patients will meet six characters (NPC, controlled by the computer), each of them having a specific story and identity. Through conversations to get precious information, these characters offer possibilities of interaction to the patients to improve their social skills. Patients thus project their personality on them, which create emotion.

All of this will be done exclusively under the supervision of the therapist who will be able to judge strategies used, will validate them (obtention of "medals"), will allow a time of observation and to take a step back. A systematic debriefing will take place at the end of each session to have a feedback with the patient on his experience, his actions, collect his feelings and to promote the transfer of learning in real life.

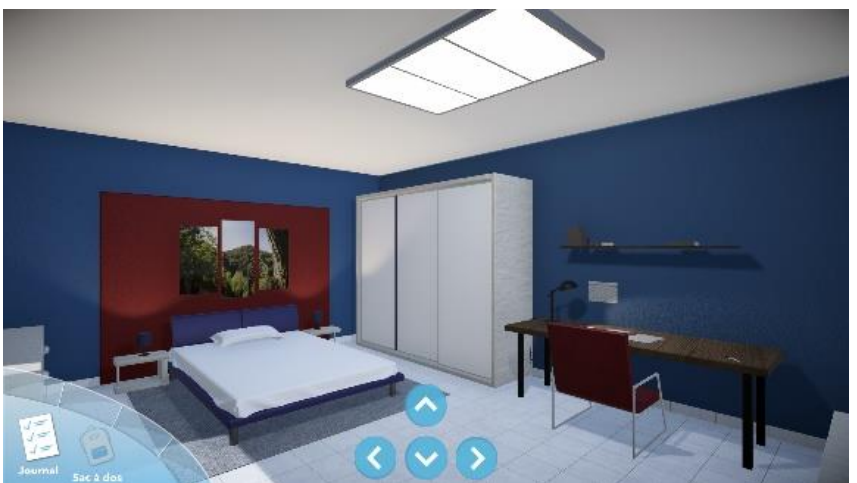

Fig. 3: Screen capture of S'TIM with its specifically designed game interface. Joystick and the bedroom.
S'TIM uses also persuasive processes. These psychological aspects lead us to work on communicative processes, especially through the use of the probability of an elaboration model. The probability of teaching indicates whether it is acceptable for a person to change his mind, or to what extent they will develop arguments about it. Thinking about it can develop or change one's attitude. This can be done in two ways: the central pathway (involving focused thinking on the subject and requiring in-depth learning resulting from a critical evaluation of information related to the subject. This thinking translated into a wall-articulated attitude) and the Peripheral way (shallower, essentially concerning the form of the message rather than its content. Modified attitudes are therefore artificial). S'TIM offers patients the opportunity to develop their strategies through the challenge they accomplish and informs them about executive functions, as well as their concrete use in everyday life (fig 4). The characters guide the patients through the game to help them find the strategies which suits them best. This central path is, however, accompanied by pleasing graphics, dialogues, etc. making the message attractive. Procedural rhetoric therefore emphasizes the therapeutic nature of the serious game while maintaining an intensity of optimal playability for thinking (a too intense game uses too much attentional resources to allow sufficient thinking and, on the contrary, a too slow one bores quickly, harm motivation and therefore interest in the message). Analytically, signs (visual, linguistic, auditory and tactile), systems (persuasive strategies that establish links between signs and that can create persuasive arguments such as narrative persuasion, kinematic persuasion and procedural persuasion) and contexts (player experience in the game, namely social persuasion to play with other people, emotional persuasion, sensory persuasion, sensory persuasion and tactile persuasion related to game challenges) can be distinguished.

In addition to the important work on interface ergonomics (Fig. 3), the game will be played on a 48-inch robotized touch table with capacitive technology and high contrasts (Fig. 5). Its height is adjustable for standing or sitting interactions, and it can be tilted to allow everyone to work comfortably. The table is therefore very easy to use for everyone, regardless of age, level of familiarity with technology, vision problems, the presence of a wheelchair, etc.

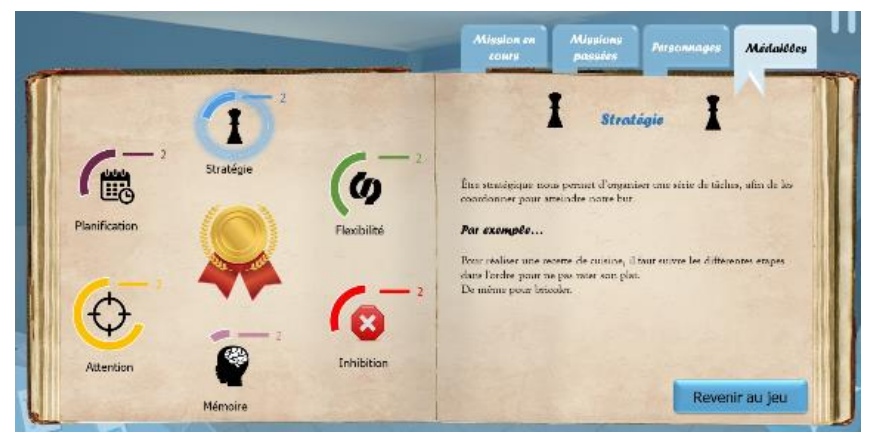

Figure 4: Screen capture of the logbook - details about the executive functions and their interest in daily life 


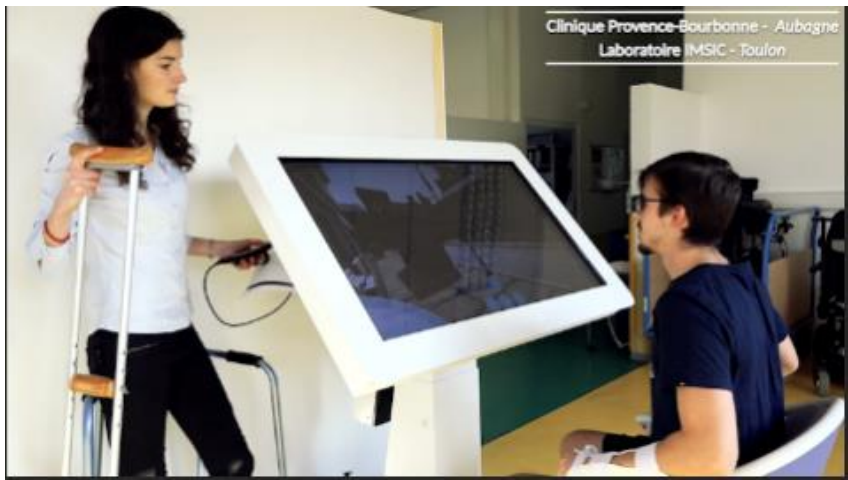

Fig. 5: The robotic touch table

Finally, every detail of the serious game as well as its use has been specified by all the experts of the consortium, with the involvement of patients and therapists since the beginning of the process. The risk of objections or rejection of the device by users are therefore reduced. Finally, every detail of the serious game as well as its use has been specified by all the experts of the consortium, with the involvement of patients and therapists since the beginning of the process. The risk of objections or rejection of the device by users are therefore reduced. At each step, iterations make it possible to check the adequacy with needs and to adjust further developments.

\section{B. Engaging communication, co-conception and support}

Persuasive communication allows to modify social representations, beliefs, attitudes and intentions of action, but it less convincing to act on effective behaviors. This brings us to the concept of engaging communication.

The project of socio-affective and socio-cognitive changes aimed therapeutically is therefore a project developed in two phases: conception and then guiding. These phases pursue complementary objectives to silence or reinforce certain actual and concrete behaviors, sometimes involving the change of counterproductive routine behavior. Individual behaviors are closely associated with the mobilization of all actors around the problem. In order for the patient to be engaged, the therapists must also be strongly involved, engaged around S'TIM. This mobilization is part of a dynamic of communication, agents have to be empowered, and precise and explicit actions have to be set up. Everyone must act for internal reasons and by acts, not for a potential symbolic reward or to avoid a sanction. The mobilization of all in the exchange and toward a clearly defined goal is built, showed and valued.

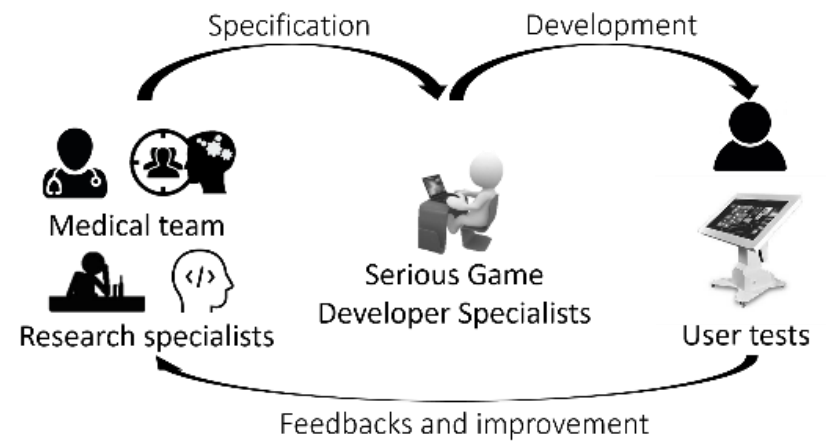

Fig. 6: Development iteration process
This phase involves defining the implemented actions, in this case individual interviews, two focus-group and brainstorming sessions. They were conducted by the engineer in Cognitics with the participation of seven occupational therapists, a rehabilitation doctor, a neuropsychologist, a health executive, an informatics researcher and patients. Rehabilitation strength and weakness, therapists and patients wishes and participants ideas about the serious game where collected and discussed. It allowed everyone to feel involved and actor of the design of S'TIM at first, to take part in the various stages of its development thereafter by suggesting modifications and improvements and finally to fully master the tool in order to better support the patients, so that they are fully engaged in their rehabilitation too. On the other hand, the purpose is to highlight the actions decided and accomplished. Iterations during the development have thus allowed teams to test each functionality and to ask for readjustments (Fig. 6). As an example, the way to move in the game (arrows, joystick and their position on the screen) has been discussed and tested before the selection of the final solution. Several presentations with direct implication of the most implicated therapists have been performed and the entire therapeutic team is regularly honored internally to enhance their involvement.

Finally, the serious game corresponds to their prescriptions and to their expectations. Interdependence of both fields of study creates favorable conditions to a relevant individual and collective action in terms of goals. Communication is therefore structuring because the action plan was built through interactions. On the "phenomenological" level, there is an observable interdependence between the link, the meaning and the action (the possibility of verbalizing in small groups frees the agents).

Thus, the paradigm of "engaging communication" associates, articulates and makes together working practically and theoretically the links of social, meaning and action, to contribute to the problematic of "existing together" in organizations. The meaning and the bond emerge from the action in the interaction.

From the patients' point of view, S'TIM having an influence on their ideas, intentions and behavior, it can impact their mood for a more or less long period of time. For this, the serious game design has been developed following several points. A work on the desired impact to determine the necessary persuasive properties was also done.

\section{Psychological needs, eudaemony and commitment}

Let's go back to the basic psychological needs as well as the increasingly dominant notion of well-being of Eudaemony in relation to the commitment. The overall scheme goes through six steps. The first one allows to anticipate the satisfaction of the user to adopt the technology (adoption). The second one fills the need for satisfaction by interaction with the interface. The third one deals with the need for satisfaction through commitment to a task enabled by a technology. The fourth is the need for satisfaction related to the behavior which is encouraged by technology. The fifth 
step is the link between technology and general well-being and finally the sixth step goes beyond the user experience (society).

Commitment mainly appears at the level of the interface, the task to perform and the type of behavior demonstrated. The need for satisfaction by interacting with the interface is a primary need manifesting itself especially on usability (a bad one leads to frustration at the level of autonomy and competence). A study by Ryan and Rigby was conducted on the elements of interfaces and their influence on the joy and commitment, particularly on social indicators ("share" button for example). In this case case, they come against the objective of S'TIM (loss of sight of the personal goal of mindfulness) so they are not exploited to privilege more significant fictional rewards (medals symbolizing the elaboration specific strategies with explanations of their use in everyday life). Social relations between patients and therapists are thus privileged. On the other hand, each challenge performed, each stage of the narration will provoke emotions, and lead to a more global behavior making the link with the next sphere. Finally, S'TIM has been developed to facilitate and enhance the development of specific behaviors in an intrinsic way. This is the highest sphere owing to the fact that being comfortable with an interface does not mean that we are comfortable with the resulting concept (eg an agenda - time in general).

Users ( 7 caregivers and 26 patients between 16 and 82 years old) did not encounter any difficulties to understand the system and the use of a touch table generated great enthusiasm and a strong implication for the exercises ("Can we work with S'TIM today?", "I find S'TIM funny" and "I think S'TIM is very useful for my rehabilitation"). Very quickly (less than one minute) installed for 5 to $30 \mathrm{~min}$ long sessions, patients were receptive and motivated. Therapists thus have an easy and pleasant tool to use as part of their practice.

\section{LIMITS AND DISCUSSION}

The device will support an in-depth clinical study on its acceptability and relevance in the context of the rehabilitation of dysexecutive disorders in 2019. For this, other rehabilitation centres will also be involved (multicentric clinical trial). This will be the subject of specific support to raise the awareness of care teams and to allow them to take ownership easily and fully before it is integrated into their therapeutic practice. Feedbacks will also be valuable for further development. Indeed, therapists keep their fundamental role with patients and they can devote themselves to the contextualization of knowledge to promote real life transfer (didactic action and no longer transmissive). The analysis of quantitative and qualitative data, so far inaccessible, may also improve understanding and therapeutic follow-up. Finally, by modifying the size of the window of the serious game, it is possible to adapt it to the different motor possibilities of the upper limbs of the patients or to work on hemineglects. Some degree of visual fatigue can be observed through the use of a screen, it is then recommended to observe appropriate practice times (about 30 minutes depending on the individual).
The short- and medium-term consequences are evaluated via surveys just after using the game for 6 weeks and then 3 months later to measure the difference between the desired and the actual behaviors.

The human-technology-organization interaction will be studied according to a "social acceptance" angle of approach by considering that technology is external to human, and that to use it humans have to accept it. This acceptance involves interventions on the interactional and psychosocial aspects. The TAM3 model of Venkatech and Bala [45] will be followed by taking $\mathrm{t}=0$ as a measure of context, sociodemographic factors and personal characteristics, including digital and health literacies. At regular intervals during the 6 weeks of reeducation on the device, a measurement of the transactional or mediating variables will be carried out in order to measure perception (affects, perceived usability, perceived hedonics, perceived affective, perceived selfefficacy) and judgments (utility, appeal). This will allow us to deduce the evolution of behavioral and emotional consequences (subjective well-being and technology-related intentions).

\section{CONCLUSION}

This innovative approach is a huge multidisciplinary challenge with major issues for patients with dysexecutive syndrome. The therapeutic serious game designed uses engagement levers, a persuasive and an engaging communication to allow to modify social representations, beliefs, attitudes and effective behaviors. At the heart of the process, the patients can develop their own mental constructs as a result of the challenges they accomplish in the scenario. Their executive functions can be tested and rehabilitated, with the supervision of therapists which make easier their concrete use in everyday life. Engaging therapists, patients and even organizations is crucial for the success of the game based therapy. Theories from Information and Communication sciences, Educational sciences, Cognitive sciences, Psychology and Neuropsychology have been involved in the design to maximize its potential. With therapists' implication since the beginning of the project, the serious game can create an opportunity in our context to improve patients' autonomy, to put them at the heart of their rehabilitation and to give them a chance to go back to their daily life. This methodology can also be used in other contexts to improve rehabilitation by engaging patients and therapists.

\section{ACKNOLEWDGMENTS}

The therapists who are implicated since the beginning of this project and the strong involvement of the Provence Bourbonne RGDS clinic, IMSIC Toulon lab and the INGEMEDIA department from Toulon university have to be acknowledged. It wouldn't be doable without them. The ANRT and Ramsay Generale de Santé Fundation for their financial support have also to be thanked. 


\section{REFERENCES}

[1] P. M. Kato, «Video games in health care: Closing the gap. », Rev. Gen. Psychol., vol. 14, $\mathrm{n}^{\circ}$ 2, p. 113-121, 2010.

[2] S. C.-I. Chen, « Technological Health Intervention in Population Aging to Assist People to Work Smarter not Harder: Qualitative Study », J. Med. Internet Res., vol. 20, n 1, p. e3, 2018.

[3] G. Giunti et A. Gomez, « Serious Games: A Concise Overview on What They Are and Their Potential Applications to Healthcare », Stud. Health Technol. Inform., 2015.

[4] Golliot Julie, Abellard Alexandre, et Durampart Michel, «Évolution de la Rééducation du Syndrome Dysexécutif grâce au Serious Game », 2017.

[5] O. Godefroy et GREFEX, « Syndromes frontaux et dysexécutifs », Rev Neurol, Paris, p. 899-909, 2004.

[6] A. Diamond, « Executive Functions », Annu. Rev. Psychol., vol. 64, p. $135-168,2013$.

[7] O. Godefroy, M. Jeannerod, P. Allain, et D. Le Gall, « Lobe frontal, fonctions exécutives et controle cognitif », Rev. Neurol. (Paris), vol. 164, Supplement 3, p. S119-S127, mai 2008.

[8] A. Baddeley, « Working Memory: Theories, Models, and Controversies », Annu. Rev. Psychol., vol. 63, n 1, p. 1-29, 2012.

[9] Golliot Julie, Abellard Alexandre, Fontugne Elodie, Herrera Cathy, Timsit Michèle, et Durampart Michel, «Un Nouveau Dispositif de Rééducation dans l'Univers des Troubles « Dys »: S'TIM, le Serious-Game Persuasif Thérapeutique Conçu pour les Patients Dysexécutifs », 2018. .

[10] K. Salen et E. Zimmerman, Rules of Play: Game Design Fundamentals. Cambridge, Mass: The MIT Press, 2003.

[11] J. Piaget, « Le prise de conscience ». Presses Universitaires de France, 1974.

[12] S. Genvo, «Penser la formation et les évolutions du jeu sur support numérique », p. 232, 2013.

[13] B. S. Greenberg, « British children and televised violence », Public Opin. $Q$, vol. 38, n 4, p. 531-547, 1974.

[14] K. Lucas et J. L. Sherry, « Sex Differences in Video Game Play:: A Communication-Based Explanation », Commun. Res., vol. 31, $\mathrm{n}^{\mathrm{o}} 5$, p. $499-523$, oct. 2004

[15] T. E. Ruggiero, « Uses and Gratifications Theory in the 21st Century », Mass Commun. Soc., vol. 3, nº 1, p. 3-37, févr. 2000.

[16] M. Gagné et E. L. Deci, « Self-determination theory and work motivation », J. Organ. Behav., vol. 26, n 4, p. 331-362, juin 2005.

[17] D. Courbet et M.-P. Fourquet-Courbet, « Les serious games, dispositifs de communication persuasive: quels processus sociocognitifs et socio-affectifs dans les usages? Quels effets sur les joueurs? Etat des recherches et nouvelles perspectives », Réseaux, vol. 33, no 194, p. 199-228, 2015.

[18] F. Bernard et R. V. Joule, « Lien, sens et action : vers une communication engageante », Commun. Organ., n 24, 2004.

[19] J. M. Burger, « The Foot-in-the-Door Compliance Procedure: A Multiple-Process Analysis and Review », Personal. Soc. Psychol. Rev., vol. 3, n 4, p. 303-325, nov. 1999.

[20] C. A. Kiesler et J. Sakumura, « A test of a model for commitment », J. Pers. Soc. Psychol., vol. 3, n 3, p. 349-353, 1966.

[21] R.-V. Joule et J.-L. Beauvois, La soumission librement consentie, 6e Edition revue et corrigée. Paris: Presses Universitaires de France - PUF, 2010.

[22] A. Korzybski, Science and Sanity: An Introduction to NonAristotelian Systems and General Semantics, Subsequent. Brooklyn, N.Y: Inst of General Semantics, 1995.

[23] J.-F. Dortier, « La perception, une lecture du monde », Gd. Doss. Sci. Hum., vol. $\mathrm{N}^{\circ} 7, \mathrm{n}^{\circ}$ 6, p. 7-7, 2007.

[24] Noémie Chaniaud, Emilie Loup-Escande, et Olga Megalakaki, «Vers un modèle intégratif de l'utilisabilité appliquée au domaine de la e-santé : quelques pistes de réflexion ».
[25] S. Barello et al., « eHealth for Patient Engagement: A Systematic Review », Front. Psychol., vol. 6, p. 2013, 2015.

[26] A. K. Knudsen et L. Kayser, « Validation of the eHealth Literacy Assessment tool (eHLA) », Int. J. Integr. Care, vol. 16, nº 6, p. A349, déc. 2016.

[27] I. Huvila, S. Ek, H. Enwald, K. Eriksson-Backa, N. Hirvonen, et H. Känsäkoski, « Taking Health Information Behaviour into Account in the design of e-health services », Finn. J. EHealth EWelfare, vol. $8, \mathrm{n}^{\circ} 4$, p. $153-163$, déc. 2016.

[28] M. Kars, L. Baker, et F. L. Wilson, Éd., The Medical Library Association guide to health literacy. New York: Neal-Schuman Publishers, 2008.

[29] N. D. Berkman, S. L. Sheridan, K. E. Donahue, D. J. Halpern, et K. Crotty, « Low health literacy and health outcomes: an updated systematic review », Ann. Intern. Med., vol. 155, n 2, p. 97-107, juill. 2011.

[30] V. L. Boudier et Y. Dambach, Serious Game: Révolution pédagogique. Paris: Hermes Science Publications, 2010.

[31] K. M. Lee, W. Peng, et N. Park, « Effects of Computer/Video Games and Beyond », in Media Effects: Advances in Theory and Research, London and New York: Routledge, 2009, p. 551-566.

[32] L. A. Annetta, « The "I's" have it: A framework for serious educational game design. », Rev. Gen. Psychol., vol. 14, n 2, p. 105-112, 2010.

[33] M. Csikszentmihalyi, Flow: The Psychology of Happiness: The Classic Work on How to Achieve Happiness, New Ed edition. London etc.: Rider, 2002.

[34] I. Bogost, Play Anything: The Pleasure of Limits, the Uses of Boredom, and the Secret of Games, 1 edition. New York: Basic Books, 2016.

[35] M. Sicart;, The Ethics of Computer Games by Miguel Sicart, Edition. MIT Press, 2011.

[36] B. Fogg, « A behavior model for persuasive design », in Proceedings of the 4th International Conference on Persuasive Technology - Persuasive '09, Claremont, California, 2009, p. 1.

[37] T. Hoffmann, S. Bennett, C.-L. Koh, et K. T. McKenna, «Occupational therapy for cognitive impairment in stroke patients », Cochrane Database Syst. Rev., nº 9, 2010.

[38] Golliot Julie, Abellard Alexandre, et Durampart Michel, «Évolution de la Rééducation du Syndrome Dysexécutif grâce au Serious Game », 2017.

[39] J. Golliot, « A new rehabilitation device: S'TIM, the persuasive and therapeutic serious-game for patients with dysexecutive syndrome », Model. Meas. Control C, vol. 79, n 4, p. 206-211, déc. 2018.

[40] Djaouti Damien, Alvarez Julian, et Jessel Jean-Pierre, « Classifying Serious Games: the G/P/S model », in Handbook of Research on Improving Learning and Motivation through Educational Games: Multidisciplinary Approaches, 2011.

[41] D. Courbet, M.-P. Fourquet-Courbet, F. Bernard, et R.-V. Joule, Communication persuasive et communication engageante pour la santé Favoriser des comportements sains avec les médias, Internet et les serious games. In press, 2013.

[42] J. T. Cacioppo et R. E. Petty, « The elaboration likelihood model of persuasion », Soc. Psychol., vol. 19, p. I23, 1986.

[43] A. V. Peterson, K. A. Kealey, S. L. Mann, P. M. Marek, et I. G. Sarason, «Hutchinson Smoking Prevention Project: long-term randomized trial in school-based tobacco use prevention--results on smoking », J. Natl. Cancer Inst., vol. 92, n 24, p. 1979-1991, déc. 2000.

[44] R. Ryan et E. Deci, « Overview of self-determination theory: An organismic dialectical perspective », in Handbook of Selfdetermination Research, University Rochester Press, 2002, p. 3-33.

[45] Viswanath Venkatesh et Hillol Bala, « Technology Acceptance Model 3 and a Research Agenda on Interventions », 2008. [En ligne]. 